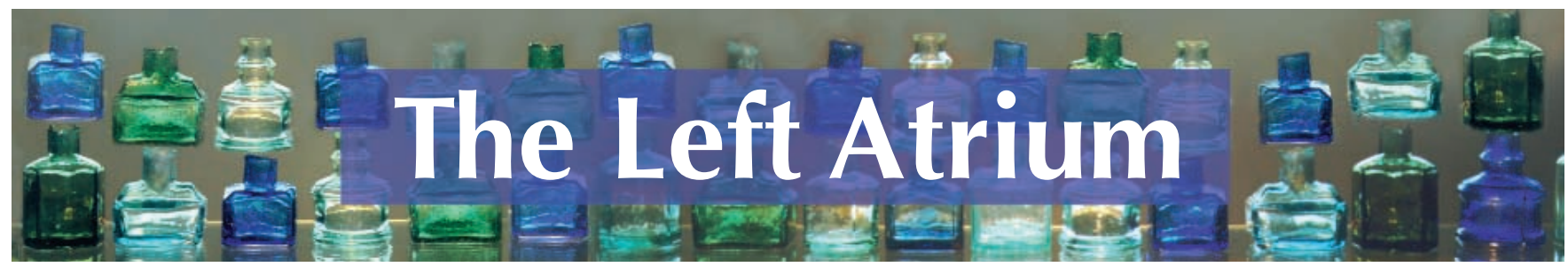

\section{Extreme nursing}

Tempting Providence

A play by Robert Chafe

Directed by Jillian Keiley

Original lighting design by Walter J. Snow

Costume design by Barry Buckle

A Theatre Newfoundland Labrador Production

National Arts Centre Studio, July 15-31, 2004

A s the story goes, Daniel's Harbour was a lucky find. A natural cove on the western shore of Newfoundland's Great Northern Peninsula, it gave lifesaving refuge to one Daniel Riggins (or Regan) and his family on a stormy day in 1821 when they were travelling from Labrador to Bonne Bay. Another kind of providence took 31-year-old Myra Grimsley, of London, England, to Daniel's Harbour exactly 100 years later. After ten years in practice as a nurse in Britain - a more comfortable setting, but one emotionally shattered by the Great War - she'd been persuaded by the wife of the Governor of Newfoundland to bring her skills to a place in dire need of nurses. She accepted a 2-year contract at $\$ 900$ a year in Daniel's Harbour, an isolated community connected to the world (weather depending) by dogsled, horse and coastal steamer. The nearest hospital was the Grenfell Mission, hundreds of miles away. The need was plain, her duty clear. Nurse Grimsley became dentist, bonesetter, midwife and guardian of public health. Within a year she also became the wife of Angus Bennett, a local ex-merchant marine; and so it was that two years spun into nearly seventy. She died in her adopted home, a centenarian.

Before her official retirement in 1953, Myra Bennett had delivered hundreds of babies and extracted thousands of teeth. Her most storied achievement was to reattach her brother-in-law's nearly-severed foot after he fell on the blade of a lumber saw. This "Florence Nightingale of the North" also practised the rational empiricism needed in public health - observing (and publishing a paper about) an association between a high incidence of breech births and the physical habits of the local women, who stooped arduously over their vegetable plots even when they were near to term.

Robert Chafe's Tempting Providence is a straight-up piece of dramatic storytelling that honours the redoubtable legacy of Myra Bennett. With a cast of two men and two women, a set consisting of four wooden chairs, a table and length of white cloth, the production was commissioned by Theatre Newfoundland Labrador (TNL) as portable fare for senior citizens' homes, schools and parish halls. Deidre Gillard-Rowlings plays a stern and decisive Nurse Bennett whose ramrod posture and clipped delivery modulates into passion only when duty transports her. Angus, played by Darryl Hopkins, is possessed of a self-deprecating irony no less resolute in its way. Making up his mind at first meeting to marry her, Angus is the only one who would dare accuse Myra of having a "depth that would make the very Atlantic blush with shame." Indeed, much of the depth we sense in Myra we see through Angus' devoted eyes. The vigorous performances of Melanie Caines as "Woman" and Robert Wyatt Thorne as "Man" provide the chorus and supporting roles, conveying the candid voices of a stalwart community - the neighbours, wise women, gossips and salts who made up Nurse Bennett's clientele along hundreds of miles of underpopulated coastline.
The play has a somewhat edifying tone and portrays Newfoundland culture in a warm light. It delivers a certain poetry, but matter-of-factly, as befits the heroine at its core. The narrative seems to assume that the obvious facts of isolation and hardship are the only points on which the audience needs to be illuminated, or won over. Myra herself becomes impatient with this theme: "You all have this big talk about winter. Like it's a terror." (Still, the audience is right to chuckle, along with Angus, at her naivveté.) The isolation is another matter. Myra finds herself in the classic position of the overworked woman: in constant demand, but nonetheless suffering from loneliness. "There is an absence here," she muses in moments of homesickness and doubt. One wants to learn a little more about the absence in her heart,

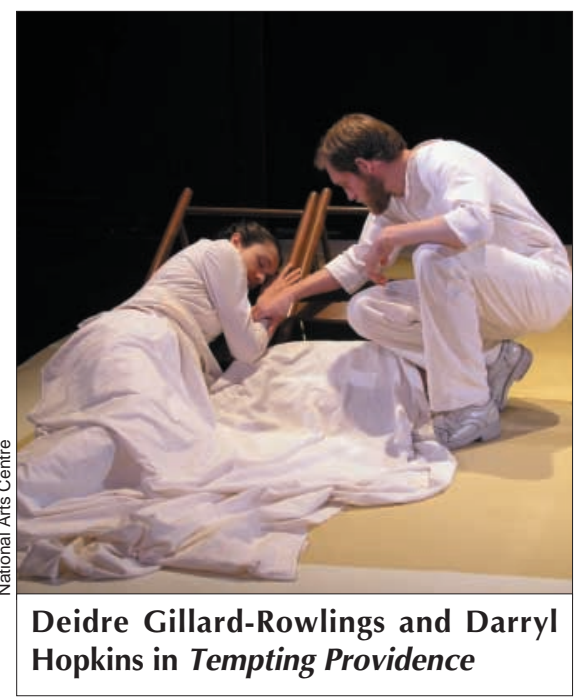

about why she needs to challenge herself to "have the courage to feel something." What is the prior, maidenly history of this dutiful adventuress?

Professional theatre, like tourism, is one of the new industries of Newfoundland After the Cod; TNL runs a popular summer repertory theatre at Gros Morne and operates a year-round professional company from Corner Brook (where all of the cast and some of the 
crew trained in the theatre program at Sir Wilfred Grenfell College). Tempting Providence made its debut at the Gros Morne Theatre Festival in 2002 to sellout crowds and was reprised the next season. Since then, the play has toured to the National Arts Centre in Ottawa in July 2004, to the prestigious Traverse Theatre venue at the Edinburgh Festival Fringe, and to multiple venues in
Ireland and England. This fall's itinerary (available at www.theatrenewfound land.com) includes intensive tours in Saskatchewan, Ontario and Atlantic Canada.

During the play's UK tour, some critics more urbane than the present one found Tempting Providence a little tame - too episodic, too straightforward, insufficiently complex. If you want cyn-

\section{My twins}

I

was looking after twins, twins with bronchiolitis.

At morning signover, whoever had been on call would tell me how much trouble the twins, those terrible twins, had been overnight. During morning rounds, I'd joke that I had only bothered to do one physical exam for the both of them. I tried, succeeding on some days and failing on others, to find some time to take with their exhausted mother, who was being worn away by the demands of her babies who were sick and the other kids at home who weren't. I struggled to remember which boy was which, eventually keeping it straight by thinking of them as "the one by the window" and "the one by the door." Consequently, I lived in terror that the nurses might, for some inscrutable purpose, switch the boys' positions. That never happened, but they did get moved to another room, and I had to adapt quickly to calling them "the one on the left" and "the one on the right." When on call at night, l'd check on the twins, those worrisome twins, and listen to the frightful difficulty of their breathing. Once or twice their nurse found me there in the middle of the night, and joined me in my fretting.

There was something weird about those boys. On admission, each was struggling to breathe, too tired to eat, and suffering from an ugly diaper rash. They were in the same shape, more or less. Then one of the boys improved, his breathing becoming less harrowing. But his brother worsened. Then he started to get better as well, but only after we got a report of a positive blood culture from a sample taken before admission. We decided it was probably a contaminated culture and nothing to worry about, but then the other one's rash got worse. One change of antifungals later, the rash was improving, but the boy got a fever. We x-rayed him and found a pneumonia.

As I wrote the order to start antibiotics, I was wondering what was going on. There seemed to be, between the two boys, a fixed and limited amount of health that was being traded back and forth. Was there only one life between the two of them, only half a life each? Would one eventually snatch all of that life away from the other?

Before I had much chance to think about this, to get into a philosophical frenzy about it, the twins, my helpless twins, started to get better. They went home with their mother, and I went on looking after other patients.

\section{Paul Moorehead}

Pediatrics Resident

Memorial University of Newfoundland

St. John's, Nfld. cisim, doubt or more than the gentlest irony, don't seek it here. Humour there is, but of a quiet kind, as in the following exchange (which ceilidh-goers on either side of the Atlantic will appreciate):

MYRA: You people, it's amazing. This perfectly nice house, with a perfectly nice parlour, couches, chairs, and you all insist upon squeezing into a kitchen the size of a closet.

ANGUS: It's a proper dance my dear. Can't stray from the kitchen.

The script is certainly episodic: an energetic, chronological run through life events, trials and accomplishments, ending with a recitation of Nurse Bennett's various life honours and awards. That being said, the flow from scene to scene is tightly choreographed and fascinating to watch as the white-clad actors-cum-stagehands swiftly transform the scene. The white cloth is transmogrified from bedsheet to wedding dress and swaddled baby; the chairs and tables are sickbed, sawtable, cradle, sled. The economical and ingenious uses of these props is itself a metaphor for the inventiveness of necessity - the self-reliance of outport life and of those nurses in remote communities who must also play the role of surgeon and doctor.

In such places, community itself is necessity's child. If there is a central, providential revelation in Myra's life as dramatized by this play, it is that the absence she grapples with is illusory. After the ordeal of the heroic surgical repair, knowing full well the dangers of infection and rejection and the virtually impossible distance to medical and surgical care, Myra's desperation reaches an anguished and almost incoherent pitch. And then she sees, materializing in the distance, figures approaching - folk from along the coast, alerted by radio and coming to help. At this moment the audience sees what Myra sees - no longer a bleak and empty landscape but a community that wills itself into being, transcending distances and sustaining anyone who finds the courage to belong.

Anne Marie Todkill CMAJ 